\title{
ANALYSIS OF SEWAGE TREATMENT PLANT AT \\ RAI, SONIPAT HARYANA
}

\author{
Abhishek Saini ${ }^{(1)}$, Geeta Singh ${ }^{(2)}$ \\ ${ }^{1}$ MTech Student, Environmental Engineering Department, DTU, Delhi, India \\ Email: - Sainiabhii02@gmail.com \\ ${ }^{2}$ Assistant Professor, Environmental Engineering Department, DTU, Delhi, India \\ Email: - Geeta.singh@dce.ac.in
}

\begin{abstract}
Almost $80 \%$ of the raw water converted into the wastewater. Wastewater treatment of Municipal waste is the way toward eliminating pollutants from civil wastewater, containing fundamentally family unit sewage including some waste from industries. This research evaluates the performance efficiency of Wastewater Treatment Plant operating on extended aeration process with the average inflow of 7.5 MLD. Fundamentally different wastewater boundaries like $\mathrm{pH}$, TSS, BOD, COD and so forth are inspected at the inlet, outlet and different various destinations of treatment plant. Investigation of quality of water of this plant is a basic as the vast majority of the treated gushing released into Yamuna waterway staying utilized for water system, watering of parks and greens. The consequences of these assessments likewise decide if the emanating released into the water body are under cut-off points given by CPCB. Wastewater tests were gathered at various phases of treatment units and investigated for the significant waste water quality boundaries, for example, BOD, COD, TSS and biodegradability. The normal convergence of boundaries at bay inspecting site $\mathrm{pH}, \mathrm{BOD}, \mathrm{COD}$, Total Suspended solids, are 7.358, $190.58 \mathrm{mg} / \mathrm{l}, 588 \mathrm{mg} / \mathrm{l}$ and $189.4 \mathrm{mg} / \mathrm{l}$ respectively. While the normal convergence of these boundaries, after treatment shows following qualities 7.792 , $7.58 \mathrm{mg} / \mathrm{l}, 32.7 \mathrm{mg} / \mathrm{l}$ and $7.8 \mathrm{mg} / \mathrm{l}$ respectively.
\end{abstract}

Keywords: Total Suspended Solids, Biological Oxygen Demand, Chemical Oxygen Demand, $\mathrm{pH}$, Wastewater treatment Plant 


\section{INTRODUCTION}

Wastewater treatment is the route toward dispensing with toxins from city wastewater, containing principally family unit sewage in addition to some modern wastewater. Physical, chemical, and biological cycles are used to dispose of foreign substances and produce treated wastewater and the process where such treatment takes place is called Sewage Treatment Plant or Wastewater Treatment Plant. Waste water can go towards treatment plants through courses by means of gravity or siphons. Mixture of water and liquid waste generated due to different activities in the community is termed as sewage.

Sewage is more than $99.9 \%$ of water and less than $0.1 \%$ of solid such that if $1000 \mathrm{~kg}$ of sewage sample is considered it consist of $0.45 \mathrm{~kg}$ of total solids out of which $45 \%$ solids are organic in nature and 55\% solids are Inorganic in nature. The wastewater isn't utilized straightforwardly for drinking purposes since it includes particles, heavy metals and microorganism and macroorganism which could be harmful to people if their focus or numbers surpasses from allowable breaking point. In this way, the need for fresh drinking water and for other people purposes, for example, water for cultivating, washing, and so on, is met by groundwater, consistently removed from ground and it additionally presents numerous natural and sociological issues in the district. The treated wastewater could go about as an option to groundwater for certain employments.

The extended aeration process employs low natural stacking, long air circulation time, high MLSS fixation and low F/M. The BOD removal efficiency is generally high in the extended aeration process. Because of long detention in the aeration tank, mixed liquor solids undergo considerable endogenous respiration and remain well stabilized. Further the excess sludge production is minimal. The oxygen requirement for the process is higher and the running costs are correspondingly high. However, operation is rendered simple due to elimination of primary settling and separate sludge digestion.

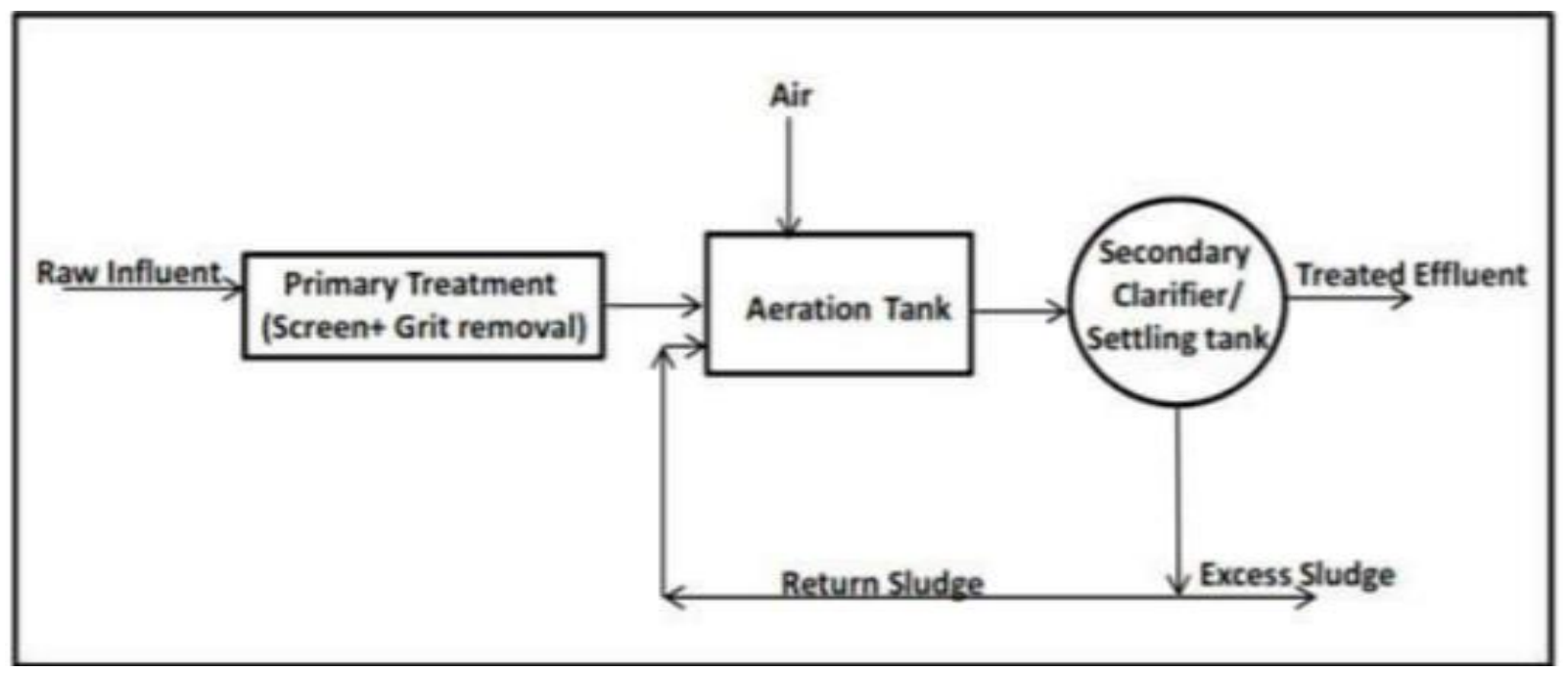

Fig. 1 - Schematic diagram show extended aeration type sewage treatment plant 


\subsection{OBJECTIVE OF THE STUDY}

I. To calculate the physio-chemical parameters at inlet, outlet and various other units of the sewage treatment plant.

II. To find out the efficiency of the sewage treatment plant.

\section{LITERATURE REVIEW}

Many previous studies were conducted on the sewage quality and have shown that treated sewage water contains very huge amount of organic contaminants as well as heavy metals concentration in the sludge generated that used for farming (Kunwar P. Singh, 2003). Another study by the (Nobuyuki Sato, 2005) concluded that the sewage treatment plant based on the combined system of UASB reactor and polishing pond were not meeting the standards led by Central Pollution Control Board.

Another study done on the effectiveness of the sewage treatment plants in the Delhi region by (Sandeep Kumar Gautam, 2012) in which they have monitored seven different Sewage different plants at different locations and they came to the conclusion that none of the available technologies on which STPs are based has direct economic return also they found out that the available technologies are unaffordable due to high capital and maintenance costs also the efficiencies were not good.

(Prashant P. Bhave, 2020) also evaluate the performance of 6 MLD Sewage treatment plant based on the Rotating Media Bio reactor over a period of 13 weeks in which they have collected samples at 6 different units and analysed the various parameters and found that all the parameters at the effluent meeting the standards led by CPCB.

\section{DESCRIPTION OF STUDY AREA}

Sonipat is a satellite town adjacent to Delhi \& falls in the NCR region. This town is being developed by HUDA on modern town planning principals. The town is located on DelhiAmbala National Highway \& well connected by Delhi Amritsar railway line. The site of STP is located adjoining Patla along EP expressway. The total area marked for STP is 25.49 acres. The site is located at latitude $28^{\circ} 55^{\prime} \mathrm{N}$ and longitude $78^{\circ} 08^{\prime} \mathrm{E}$ in Sonipat district, Haryana. Effluent is discharged into the Yamuna river and remaining used for the gardening purposes. The plant uses Extended aeration technology for the biological treatment of the wastewater. Samples were collected at inlet, outlet and the various other units of the sewage treatment plant. 3 different sampling locations were considered within a treatment plant. The samples were collected at inlet or receiver chamber, after aeration tank and at outlet location. 
Table 1 Waste Water Treatment Plant Details

\begin{tabular}{lll}
\hline $\mathbf{S}$ no & Wastewater Treatment Unit & No of Units \\
\hline $\mathbf{1}$ & Inlet Chamber & 1 \\
\hline $\mathbf{2}$ & Screening & $(1 \mathrm{~W}+1 \mathrm{~S})$ \\
\hline $\mathbf{3}$ & Grit Chamber & $(1 \mathrm{~W}+1 \mathrm{~S})$ \\
\hline $\mathbf{4}$ & Aeration Tank & 2 \\
\hline $\mathbf{5}$ & Secondary Clarifier & 1 \\
\hline
\end{tabular}

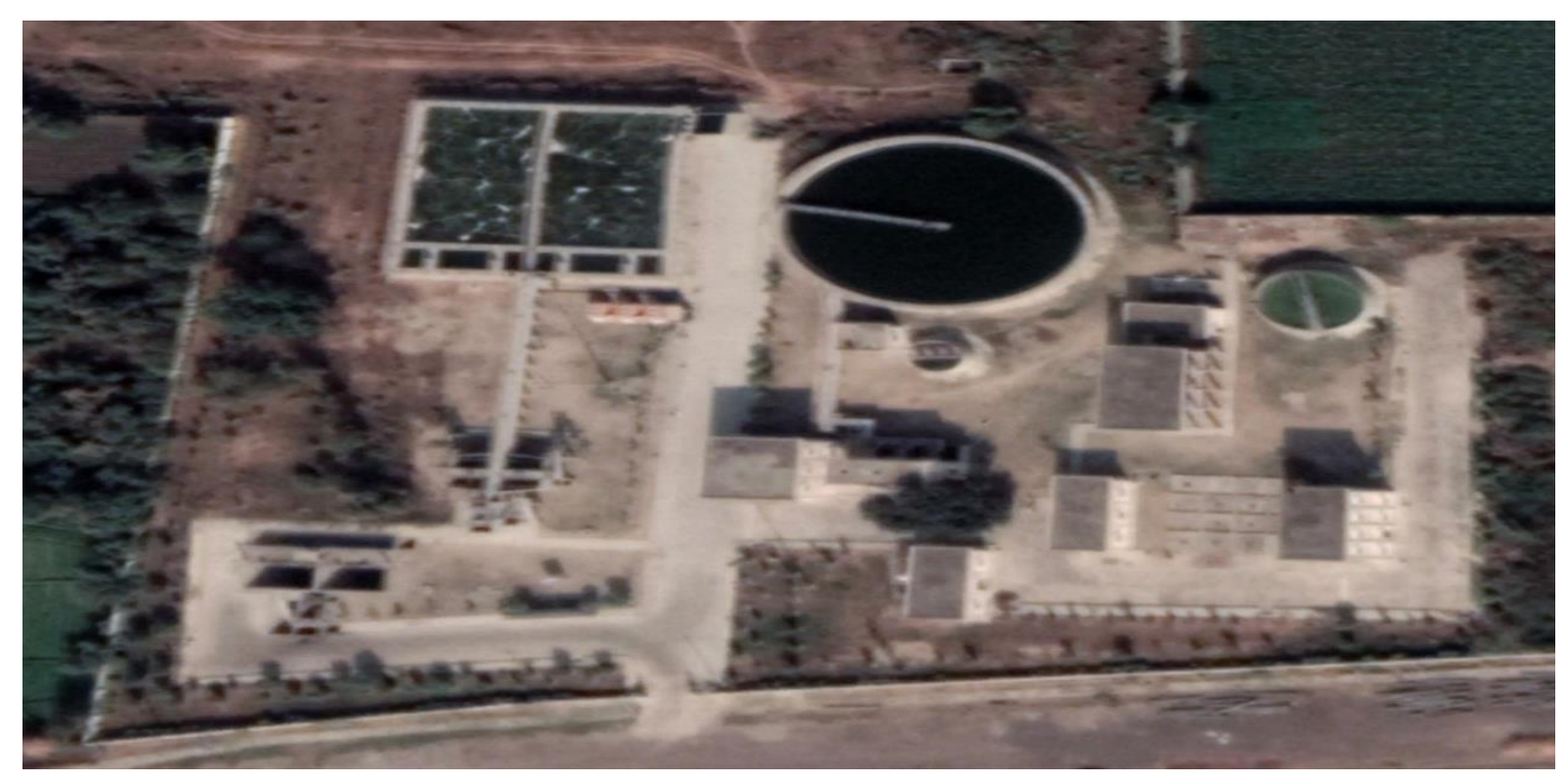

Fig 2 Satellite view of the Sewage treatment plant 


\section{MATERIALS \& METHODOLOGY}

In the underlying period of the examination, the data and subtleties related to treatment measures, working of plants units, data with respect to sludge disposal, and so forth were gathered for sewage treatment plant. At that point, examining area was chosen from the inlet and outlet of various units of the treatment plant. The term of the study is from October 2020 to January 2021, during which tests at customary stretch were taken from every one of the working unit's inlet and outlet separately. The performance of existing sewage treatment plants was evaluated by collecting samples from the sewage treatment plant and analysing samples at STP lab at PATLA village SONIPAT. The experiment involves the collection of samples by using grab sampling in clean plastic containers of 2-1 capacity by following IS 3025-1 Methods of Sampling and Test (Physical and Chemical) for Water and Wastewater 1999. The sample storage is done as per the norms by the Central Pollution Control Board (CPCB) and EPA guidelines. The samples were analysed for various pollution parameters by conducting a laboratory test which includes total suspended solids, chemical oxygen demand, and biochemical oxygen demand as per standard methods.

Table 2 Details of Sampling location of Sewage Treatment Plant

\begin{tabular}{lll}
\hline S No & Location Name & Details of sampling \\
\hline $\mathbf{1}$ & S1 & The inlet chamber \\
\hline $\mathbf{2}$ & S2 & After aeration Tank \\
\hline $\mathbf{3}$ & S3 & Outlet ( After chlorination ) \\
\hline
\end{tabular}

Table 3 Biological oxygen demand (BOD) in $\mathrm{mg} / \mathrm{l}$

\begin{tabular}{llllll}
\hline Sample & Week 1 & Week 3 & Week 5 & Week 7 & Week 9 \\
\hline Inlet & 180 & 193 & 206.6 & 160 & 213.3 \\
\hline After aeration & 72 & 73.34 & 120 & 53 & 70.39 \\
\hline Outlet & 6.6 & 6.8 & 10 & 7 & 7.5 \\
\hline
\end{tabular}

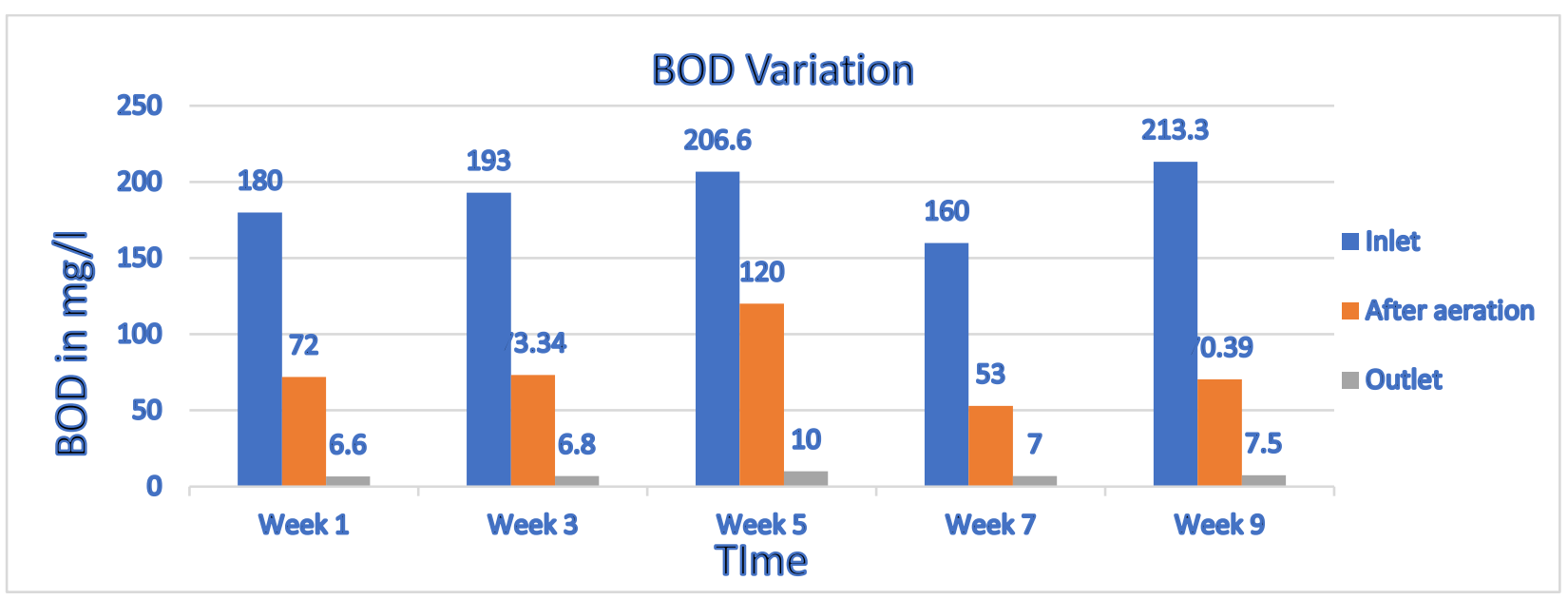

Figure 3 BOD variation 
Table 4 Chemical Oxygen Demand (COD) in mg/l

\begin{tabular}{llllll}
\hline Sample & Week 1 & Week 3 & Week 5 & Week 7 & Week 9 \\
\hline Inlet & 540 & 660 & 620 & 480 & 640 \\
\hline After aeration & 135 & 100 & 250 & 80 & 100 \\
\hline Outlet & 20 & 19.5 & 80 & 21.5 & 22.5 \\
\hline
\end{tabular}

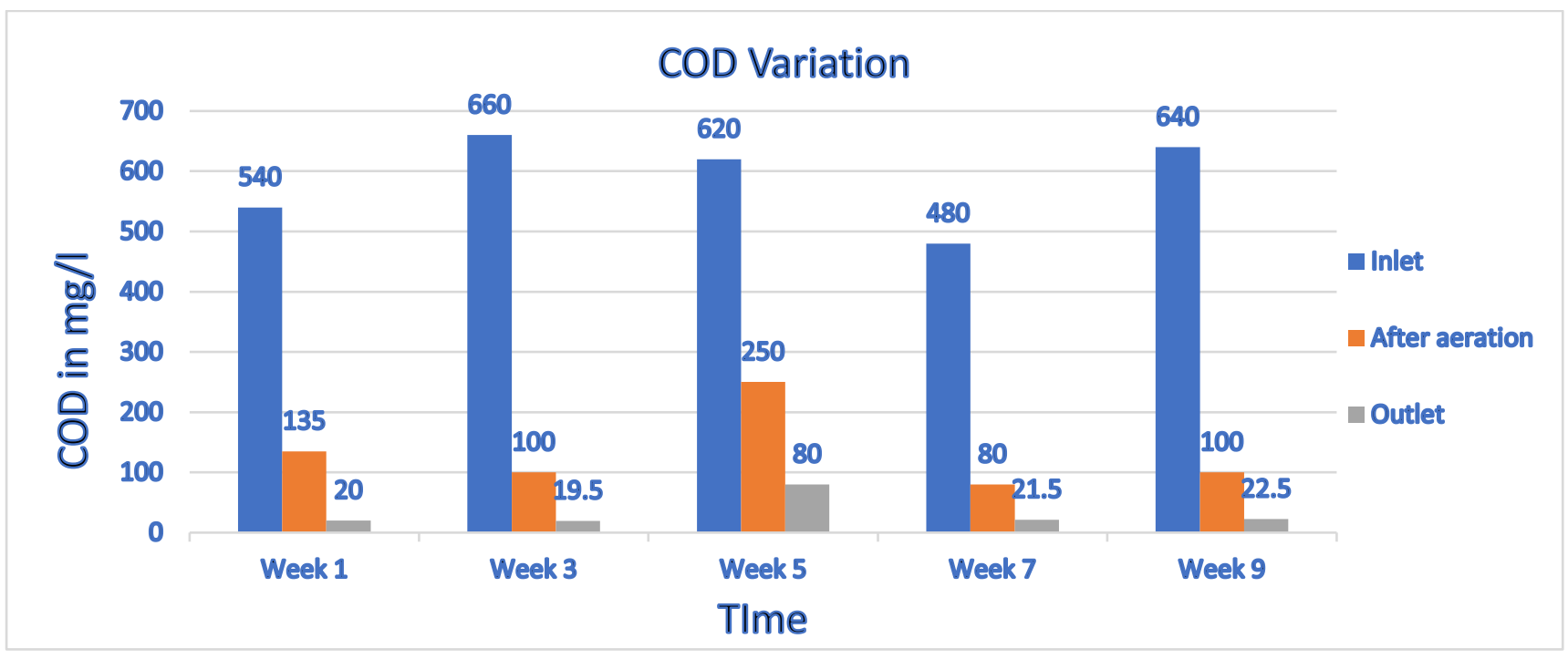

Figure 4 COD variation

Table 5 Total Suspended Solids (TSS) in $\mathrm{mg} / \mathrm{l}$

\begin{tabular}{llllll}
\hline Sample & Week $\mathbf{1}$ & Week $\mathbf{3}$ & Week $\mathbf{5}$ & Week $\mathbf{7}$ & Week 9 \\
\hline Inlet & 140 & 186 & 218 & 211 & 192 \\
\hline After aeration & 21 & 37 & 90 & 45 & 20 \\
\hline Outlet & 6 & 7 & 9 & 10 & 7 \\
\hline
\end{tabular}

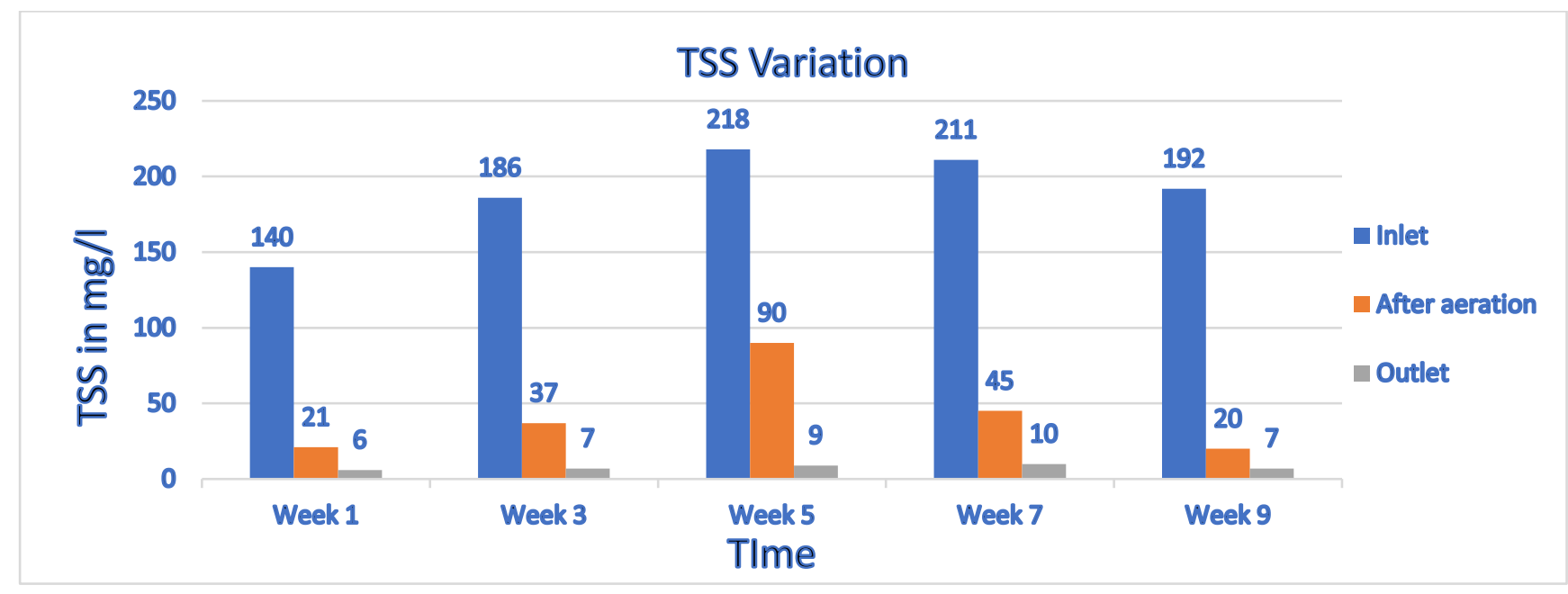

Figure 5 TSS variation 
Table 6 Biodegradability variation

\begin{tabular}{llll}
\hline Sample & BOD & COD & Biodegradability \\
\hline Week 1 & 180 & 540 & 0.33 \\
\hline Week 3 & 193 & 660 & 0.29 \\
\hline Week 5 & 206.6 & 620 & 0.33 \\
\hline Week 7 & 160 & 480 & 0.33 \\
\hline Week 9 & 213.3 & 640 & 0.33 \\
\hline
\end{tabular}

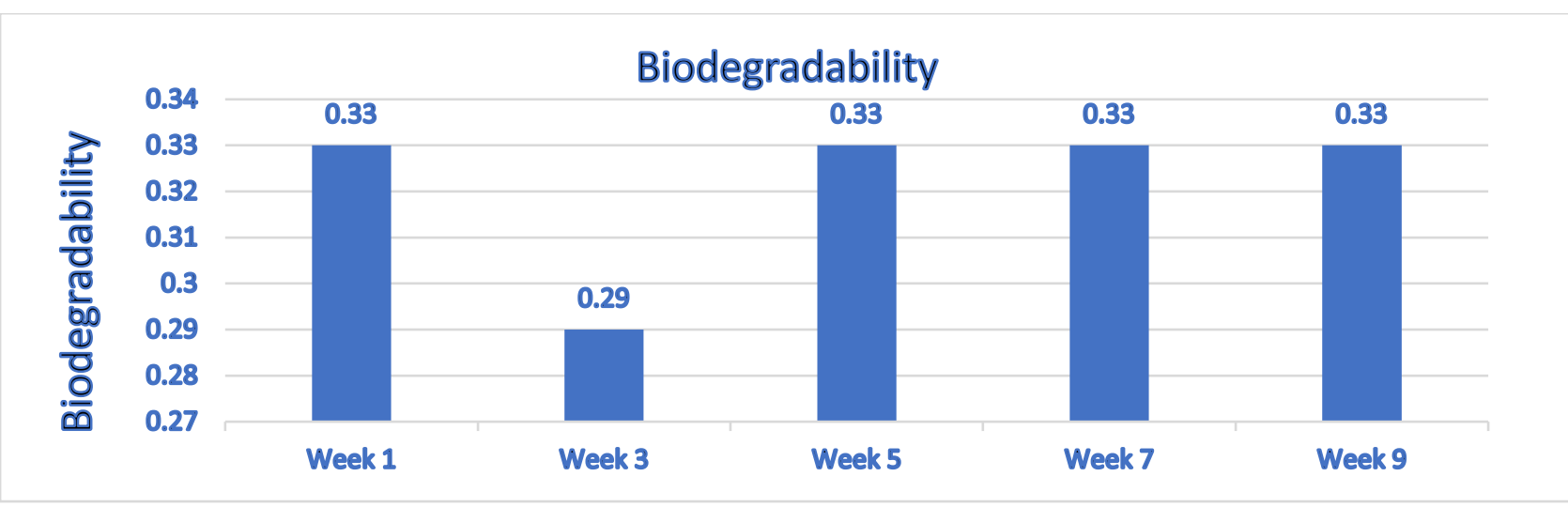

Figure 6 Biodegradability of raw waste water

Table $7 \mathrm{pH}$ variation

\begin{tabular}{llllll}
\hline Sample & Week 1 & Week 3 & Week 5 & Week 7 & Week 9 \\
\hline Inlet & 7.3 & 7.39 & 7.34 & 7.4 & 7.36 \\
\hline After aeration & 7.5 & 7.54 & 7.55 & 7.56 & 7.6 \\
\hline Outlet & 7.75 & 7.78 & 7.8 & 7.83 & 7.8 \\
\hline
\end{tabular}

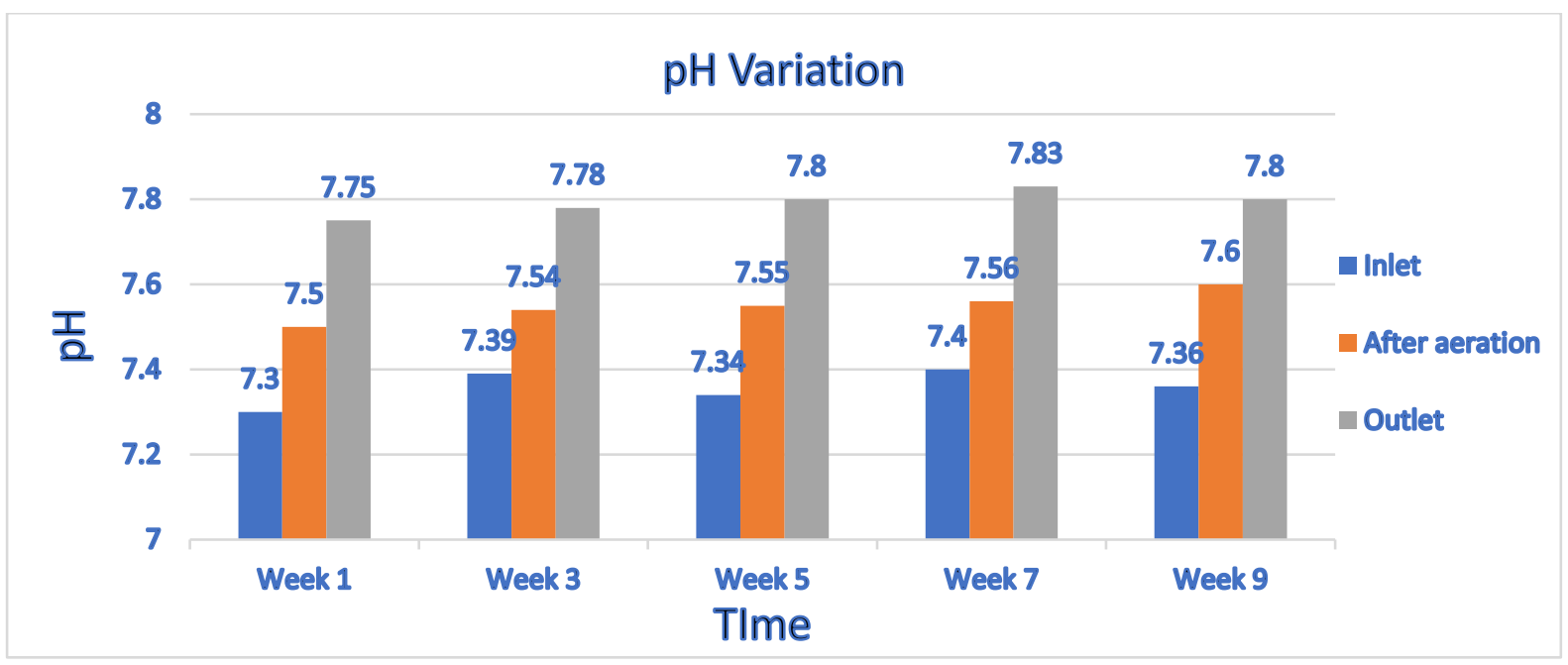

Figure $7 \mathrm{pH}$ variation 


\section{RESULTS \& DISCUSSION}

The wastewater samples were collected at various locations of the sewage treatment plant and analysed. The $\mathrm{pH}$ of the wastewater slightly increased from inlet at 7.3 to 7.8 also it is slightly increasing as wastewater processes to the different units. The Total Suspended values vary from $250 \mathrm{mg} / \mathrm{l}$ at inlet to $6 \mathrm{mg} / \mathrm{l}$ at the outlet. The maximum effectiveness for the expulsion of COD was $97.04 \%$ which was accomplished for the week 3 and the least efficiency was seen at $59.67 \%$ for week 5 (Table 4; Fig. 4). The COD of wastewater before treatment was ranging from 480 to $660 \mathrm{mg} / \mathrm{l}$ and COD of the water after treatment was ranging from 19.5 to $80 \mathrm{mg} / \mathrm{l}$. Biodegradability is generally the proportion of BOD/COD and is generally calculated to know the quality of the raw water so that it can easily predicted whether it is biodegradable or non biodegradable. This ratio or proportion helps to choose the suitable treatment process for the influent raw water (Table 6; Fig. 6). The values of biodegradability of inlet wastewater are varied from 0.29 to 0.33 . During the analysis period, the average value of BOD/COD or biodegradability of inlet raw wastewater was 0.322 . The maximum effectiveness for the expulsion of BOD was $96.48 \%$ which was accomplished for week 9 , and the least efficiency was seen at $95.16 \%$ for week 5 (Table 3; Fig. 3). The Biological Oxygen Demand of wastewater before treatment varied from 160 to $213.3 \mathrm{mg} / \mathrm{l}$, and after treatment varied from 6.6 to $10 \mathrm{mg} / \mathrm{l}$.

\section{CONCLUSION}

The examination meant to assess the presentation proficiency of different units in the wastewater treatment plant. The COD evacuation proficiency of in general plant changes from 87.10 to $97.04 \%$ during the examination time frame. The general normal COD evacuation productivity of the treatment plant was discovered to be $94.49 \%$. The BOD expulsion proficiency of generally speaking plant changes from 95.16 to $96.48 \%$ during the investigation period. The general normal BOD expulsion proficiency of the treatment plant is $95.91 \%$. The TSS evacuation proficiency of by and large plant differs from 95.26 to $96.34 \%$ during the investigation time frame. The general normal TSS evacuation productivity of the treatment plant is $93.27 \%$. The normal estimation of biodegradability for bay crude water in present examination was 0.322. During the investigation time frame the emanating tests from the sewage treatment plant were found to meet the spring release principles indicated by Central or State Pollution Control Board (CPCB) or (SPCB). The biodegradability of raw water was 0.322 which shows that water have toxic contents present in it. It has been concluded that some of the municipal wastewater got mixed with the wastewater from the industries which increases its toxic content. Proper care shall be required otherwise the treated water used for irrigation and sewage farming may contain heavy metals which lead to the ground contamination.

\section{ACKNOWLEDGEMENT}

I would like to take this opportunity to express my profound gratitude and deep regard to my guide (Geeta Singh) for her exemplary guidance, valuable feedback, constant encouragement and supported me at every bit and without her it was impossible to accomplish the end task. 


\section{REFERENCES}

1. Bhakti Kulkarni, R. W. (2016). Study On Sewage Quality From Sewage Treatment Plant At Vashi, Navi Mumbai. Materials Today, 5.

2. Charu Sharma, S. S. (2013). Performance Evaluation Of Sewage Treatment Plant Based On Advanced Aerobic Biological Filtration And Oxygenated Reactor (BIOFOR) Technology- A Case Study Of Capital City -Delhi, India. International Journal of Engineering Science and Innovative Technology, 9.

3. Derin Orhon, E. A. (1996). CHARACTERIZATION AND COD FRACTIONATION OF DOMESTIC WASTEWATER. Environmental Pollution, 14.

4. Dipu Sukumaran, R. S. (2015). Performance Evaluation of Prevailing Biological Wastewater Treatment Systems in West Bengal, India. Science and Education Publishing, 5.

5. Eddy, M. a. (2014). Wastewater Engineering Treatment and Resource Recovery. New York: McGraw Hill Education.

6. Kunwar P. Singh, D. M. (2003). Impact assessment of treated/untreated wastewater toxicants discharged by sewage treatment plants on health, agricultural, and environmental quality in wastewater disposal area. Chemosphere, 29.

7. Mouchel, P. J. (2009). Efficiency evaluation of sewage treatment plants with different technologies in Delhi (INDIA). Environmental Monitoring and Assessment •, 13. Retrieved from 10.1007/s 10661-008-0356-9

8. Mouchel, P. J.-M. (2008). Efficiency evaluation of sewage treatment plants with different technologies in Delhi (India). Environmental Monitoring and Assessment, 14.

9. Nobuyuki Sato, T. O. (2005). Prospects for a self-sustainable sewage treatment system: A case study on full-scale UASB system in India's Yamuna River Basin. Environment Management, 10.

10. Prashant P. Bhave, S. N. (2020). Performance Evaluation of Wastewater Treatment Plant. Water Conservation Science and Engineering, 7.

11. Sandeep Kumar Gautam, D. S. (2012). A study of the effectiveness of sewage treatment plants in Delhi region. Appl Water Science, 10.

12. Zhu, S. R. (2018). Wastewater Treatment and Reuse. New York: Taylor and Francis Group. 